\title{
Study the Possibility of Implementing a Solar Chimney Power Plant in Algeria (Case study: Constantine)
}

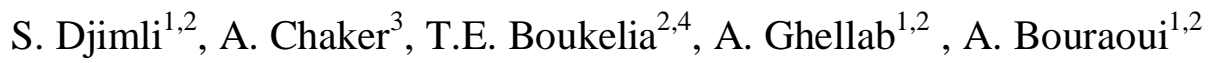 \\ ${ }^{1}$ Laboratory of Applied Energies and Materials, Faculty of Sciences and the Technology, \\ Ouled Aissa BP 98, University of Jijel, Algeria \\ Phone/Fax number: +0021334501400, e-mail: djsamir.25@gmail.com \\ ${ }^{2}$ Mechanical Engineering Department, Faculty of Sciences and the Technology, \\ Ouled Aissa BP 98, University of Jijel, Algeria \\ Phone/Fax number: +0021334501400 \\ ${ }^{3}$ Energy Physics Laboratory, Department of Physics, University of Brothers Montouri Constantine1, \\ Constantine, Algeria \\ Phone/Fax number: +0021331811271, e-mail: chakamine@yahoo.fr \\ ${ }^{4}$ Laboratory of Mechanical and Advanced Materials, Polytechnic School of Constantine, \\ Constantine, Algeria \\ Phone/Fax number: +0021331785168, e-mail: taqy25000@hotmail.com
}

\begin{abstract}
This work offers the opportunity to consider the possibility of realizing a solar chimney power plant in the region of Constantine (Algeria). This region is characterized by its important solar radiation resource and ambient temperature. Based on actual measurements of Constantine weather station for the period of April 2020, the performance analysis of a solar chimney which have three times the dimensions of the Manzaneres prototype (Spain) is carried out using of Fluent software. The obtained results show that when the dimensions of the solar chimney are large, the impact of small changes in solar irradiation is negligible. Also, the studied power plant with dimensions of; $584 \mathrm{~m}$ height, a diameter of $30 \mathrm{~m}$ and a collector diameter of $732 \mathrm{~m}$ is capable of producing a monthly average of 72 to $296 \mathrm{MW}$ of electrical energy, this energy production would be sufficient to meet the needs of rural areas located in this region.
\end{abstract}

\section{Key words}

Constantine, performance, solar energy, solar chimney/tower, solar collector

\section{Introduction}

The rapid increases in population and economic development have led to a growing demand for energy. The unavoidable exhaustion of fossil fuels along with their more polluting effects changes the direction of efforts and research into renewable energy sources.

Solar energy is one of the great hopes of mankind. Many applications of this inexhaustible and proenvironmental source are known. Among them is the solar chimney power plant used to produce electrical energy from sunlight.

This type of electrical power generators introduced by J. Schlaich Stuttgart in 1968 [1] consists of three main components [2]: a solar collector (based on greenhouse effect), a chimney (tower), and a wind turbine.

As presented in Fig 1, air is heated up by solar radiation under a low circular glass roof open at the periphery. Continuous 24 hours-operations are guaranteed by placing tight water-filled tubes under the roof. The water heats up during the daytime and emits its heat at night. These tubes are filled only once, then, no further water is needed. In the middle of the roof, there is a vertical chimney with large air inlets at its bottom. The joint between the roof and the chimney bottom is airtight. As hot air is lighter than cold air, it rises up the chimney. Suction from the chimney then draws in more hot air from the collector, and cold air comes in from the outer perimeter. Thus, solar radiation causes a constant up draught in the chimney. The energy contained in the hot air is converted into mechanical energy by pressurestaged wind turbines at the bottom of the chimney, and into electrical energy by conventional generators [1]. Asnaghi et al. [3] leaned over into the study of the possibility of implantation a solar chimney plant in 12 regions located in the central Iran; this plant could produce between 10 to $28 \mathrm{MWh}$ per month of electrical energy. While Dai et al [4] carried out a study to build a power station in villages in northwest China, with dimensions of $200 \mathrm{~m}$ height of the chimney, a diameter of $10 \mathrm{~m}$, and a collector diameter of $500 \mathrm{~m}$, which can produce a net output of 110 to $190 \mathrm{KW}$ of electric power throughout the year. On the other hand, Djimli et al. [5] examined the installation of a solar chimney power plant in the region of M'Sila (Algeria) with the same prototype characteristics of Manzaneres (Spain), to produce a net output of 39 to $72 \mathrm{~kW}$. In addition, the same authors [6] carried out a second investigation on the possibility of installing a solar chimney power plant across the national territory of Algeria (Algiers, Batna, Bechar and Ghardaia). The obtained results showed that the 
production of electrical energy is almost the same in all regions during spring and summer. However, for other seasons, the production in the southern regions (Bechar and Ghardaia) is much better. On the same wave, Okoye et al. [7] studied the technical feasibility of installing a solar chimney power plant in the northern region of Turkey. The authors have shown that a solar chimney that would produce a capacity of $30 \mathrm{MW}$ could meet the annual electricity needs of more than 22,128 homes, without significant environmental impact.

The prototype of Manzanares in Spain is the only solar chimney of industrial scale in the world that was built and tested over the years 1982-1989 [8]. Many other projects were announced in different countries (India, Australia, China, Namibia, USA, Chile ...), but none has emerged.

In this work, the possibility of implementing a solar chimney power plant in the region of Constantine (Algeria), in which the solar potential is exceptional is investigated. Thus, our main focus is to explore the performances and yield of such a facility in the aforementioned location.

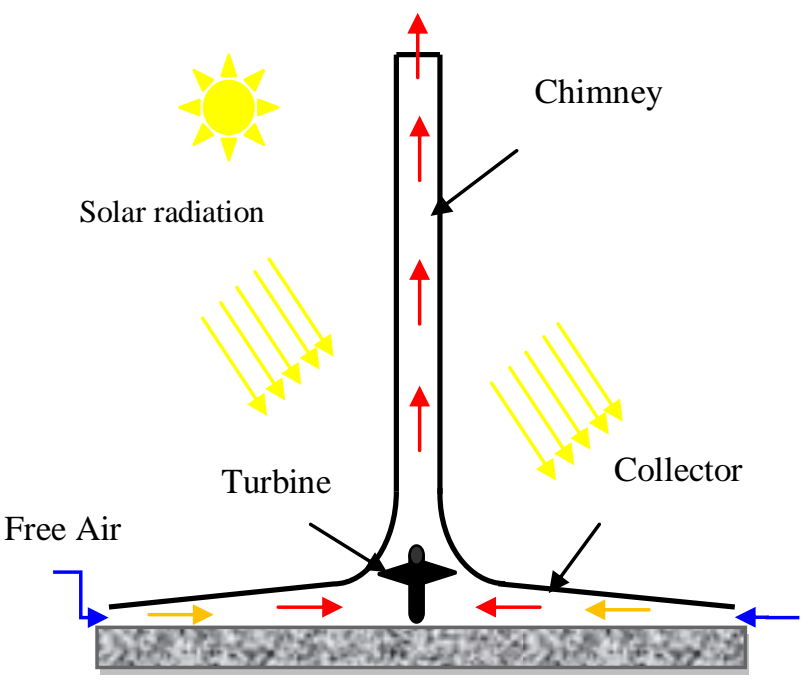

Fig. 1. Solar chimney

\section{Mathematical Model and Boundary Conditions}

The geometry of the solar chimney, which is illustrated in Fig 2, consists of two cylindrical cavities. They are open and superimposed on each other (the chimney and collector). The characteristics of the rotational symmetry of the cylinder makes the solution two-dimensional depends only on two dimensions ( $\mathrm{r}$ and $\mathrm{z}$ ).

The equations that describe the flow in cylindrical coordinates are given by [9]:

- Mass conservation:

$\frac{u}{r}+\frac{\partial u}{\partial r}+\frac{\partial v}{\partial z}=0$
- Linear r-momentum conservation:

$$
\begin{aligned}
u \frac{\partial u}{\partial r} & +v \frac{\partial u}{\partial z} \\
& =\frac{\mu}{\rho}\left(\frac{u}{r^{2}}+\nabla^{2} u\right)+\frac{-1}{\rho} \frac{\partial p}{\partial r}
\end{aligned}
$$

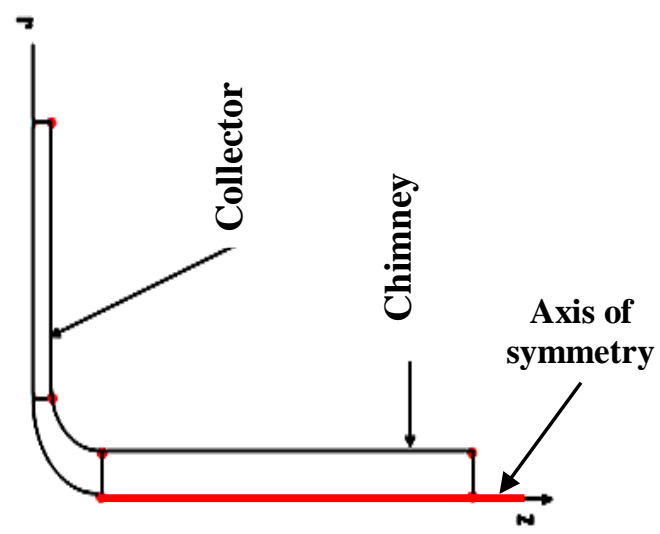

Fig. 2. Two-dimensional geometric of the solar chimney

- Linear z-momentum conservation:

$\frac{\partial v}{\partial r}+v \frac{\partial v}{\partial z}=\frac{\mu}{\rho} \nabla^{2} v+\frac{-1}{\rho} \frac{\partial p}{\partial z}-\frac{\rho_{T}}{\rho} g$

- Energy conservation:

$u \frac{\partial T}{\partial r}+v \frac{\partial T}{\partial z}=\alpha \nabla^{2} T$

- The model of turbulence [10] used is $k-\varepsilon$.

A. Solar collector: The efficiency of collector is given by [3]: $\quad \eta_{\text {coll }}=\frac{\dot{Q}}{A_{\text {coll }} \cdot G}$

Where the heat generated $\dot{Q}$ and air mass flow $\dot{m}$ are given by equations 6 and 7 respectively: $\dot{Q}=\dot{m} \cdot C_{p} . \Delta T$

$\dot{m}=\rho_{\text {coll }} \cdot V_{c} \cdot A_{c}$

By substituting $\dot{Q}$ and $\dot{m}$ in Equation 6, by their expressions, we obtain the global relation of plant's efficiency:

$$
\eta_{\text {coll }}=\frac{\rho_{\text {coll }} \cdot V_{c} \cdot A_{c} \cdot C_{p} \cdot \Delta T}{A_{\text {coll }} \cdot G}
$$

B. solar chimney: The efficiency of the chimney can be expressed either by [3]:

$\eta_{s c}=\frac{g H_{s c}}{C_{p} T_{a t m}}$ 
While the electrical power is given by [3]:

$$
P_{e}=\frac{2}{3} \eta_{c o l l} \eta_{w t} \frac{g}{C_{p} T_{0}} H_{s c} A_{c o l l} G
$$

Where $\eta_{w t}$ and $2 / 3$ are the turbine efficiency and the pressure drop in the turbine respectively.

In order to solve the problem numerically, the boundary conditions and the geometrical parameters used in the calculations are recorded in Tables I and II.

Table I. - Assumed boundary conditions to perform the simulations $[5,6]$

\begin{tabular}{|l|l|l|}
\hline Place & Type & Value \\
\hline Bottom of the collector & Heat flow & $\mathrm{F}\left(\mathrm{W} / \mathrm{m}^{2} \mathrm{~K}\right)$ \\
\hline Top of the collector & convection & $\mathrm{T}_{\mathrm{atm}}, \mathrm{h}=10 \mathrm{~W} / \mathrm{m}^{2} \mathrm{~K}$ \\
\hline Surface of the chimney & Adiabatic & $\mathrm{qsc}=0 \mathrm{~W} / \mathrm{m}^{2} \mathrm{~K}$ \\
\hline Collector inlet & Pressure inlet & $\mathrm{P}=\mathrm{P}_{\mathrm{atm}}, \mathrm{T}=\mathrm{T}_{\mathrm{atm}}$ \\
\hline Chimney outlet & Pressure outlet & $\mathrm{P}=\mathrm{P}_{\mathrm{atm}}$ \\
\hline
\end{tabular}

Table II. - Dimensions and inputs defined in the study.

\begin{tabular}{|c|c|l|c|}
\hline \multicolumn{1}{|c|}{ Parameters } & Value & \multicolumn{1}{|c|}{ Parameters } & Value \\
\hline Chimney height $\left(\mathrm{H}_{\mathrm{sc}}\right)$ & $584 \mathrm{~m}$ & $\begin{array}{l}\text { Product of } \\
\text { transmittance and } \\
\text { absorbance of the } \\
\text { collector } \alpha \tau_{[6]}\end{array}$ & 0,65 \\
\hline Chimney diameter $\left(\mathrm{D}_{\mathrm{sc}}\right)$ & $30 \mathrm{~m}$ & $\begin{array}{l}\text { Collector diameter } \\
\left(\mathrm{D}_{\text {coll }}\right)\end{array}$ & $\begin{array}{c}732 \\
\mathrm{~m}\end{array}$ \\
\hline $\begin{array}{c}\text { Distance from ground to } \\
\text { the cover }\left(\mathrm{H}_{\text {coll }}\right)\end{array}$ & $5,6-11 \mathrm{~m}$ & 0,85 \\
\cline { 1 - 3 } $\begin{array}{c}\text { Efficiency of the turbine } \\
\eta_{w t}\end{array}$ & & \\
\hline
\end{tabular}

\section{Results and Discussion}

\subsection{Validation}

Initially, the Spanish Prototype geometry [11] is modeled and solved numerically based on the assumed boundary conditions. In order to validate the adopted method of this study, and according to the experimental data [11], solar radiation should be $1000 \mathrm{~W} / \mathrm{m}^{2}$, while the velocity near the entrance chimney should be $15 \mathrm{~m} / \mathrm{s}$ with $20 \mathrm{~K}$ temperature rise in the collector. Sangi et al. [12] and Ghorbani et al. [13] have also redesigned the prototype to validate their solutions. Their numerical and experimental results and the results of the current study are shown in Table III. There is a good agreement between our numerical process and literature.

Tableau III. - Validation of the numerical modelling.

\begin{tabular}{|l|l|l|l|}
\hline \multicolumn{1}{|c|}{ Study } & $\begin{array}{c}\text { Temperature } \\
\text { rise }\end{array}$ & \multicolumn{1}{|c|}{$\begin{array}{c}\text { Upwind } \\
\text { velocity } \\
\mathrm{m} / \mathrm{s}\end{array}$} & \multicolumn{1}{|c|}{$\begin{array}{c}\text { Power } \\
\text { output } \\
\mathrm{KW}\end{array}$} \\
\hline Experimental study [11] & 20 & 15 & 50 \\
Sangi et al.[12] & 20,25 & 15,05 & $/$ \\
Ghorbani et al[13]. & 20,22 & 15,06 & $/$ \\
Our results & $\mathbf{1 9 , 7 5}$ & $\mathbf{1 4 , 9 6}$ & $\mathbf{5 0 , 5 6}$ \\
\hline
\end{tabular}

\subsection{Impact of solar irradiation and ambient temperature on the performances}

The performance of the chimney solar power plant is closely related to solar irradiation and ambient temperature [5, 6]. First, the review of these key parameters will be presented. The evolution of global solar radiation and ambient temperature during the month of April 2020 in the region of Constantine (Algeria) is illustrated in figure 3 .

The figure 3 is showing the monthly evolution of the average daily solar radiation and ambient temperature. The examination of the curves (in figure 3 ) shows that the two curves do not have the same shape, else in some days the solar radiation is important but the temperature is low (example 04/12/2020). While in other days, the temperature is high despite that the radiation is low $(04 / 26 / 2020)$, and the solar radiation varies approximately during the month from $25 \mathrm{~W} / \mathrm{m}^{2}$ up to 120 $\mathrm{W} / \mathrm{m}^{2}$ and ambient temperature from $282 \mathrm{~K}$ to $292 \mathrm{~K}$.

Also, it should be machined that the maximum value of solar irradiation for the region of Constantine is in the range of $360 \mathrm{~W} / \mathrm{m}^{2}$.

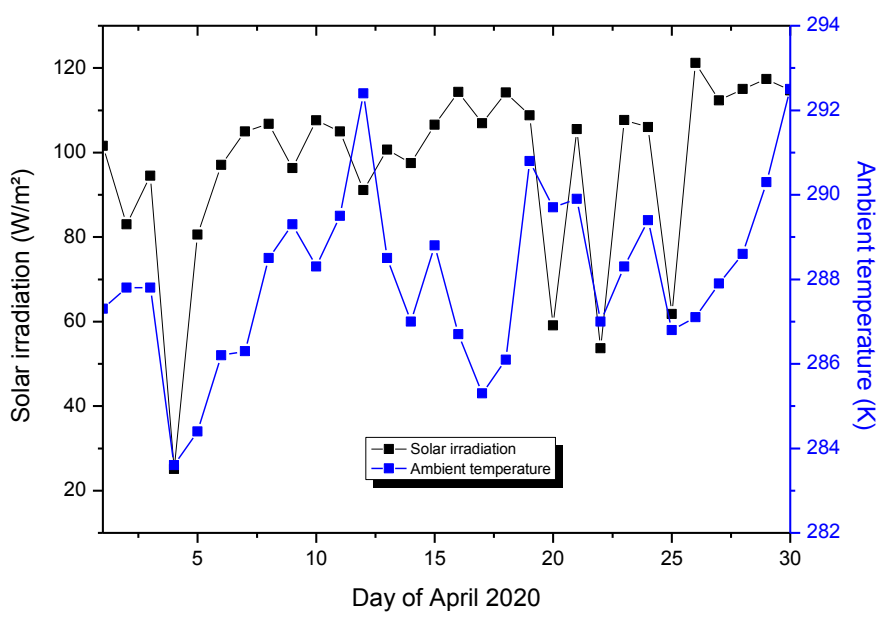

Fig. 3. Solar irradiation and ambient temperature during the month of April 2020 (Ain El Bey Constantine weather station).

In order to deepen our investigation on the considered site, the evolution of solar radiation and ambient temperature of nine (9) days of April is shown in Figures 4-12.

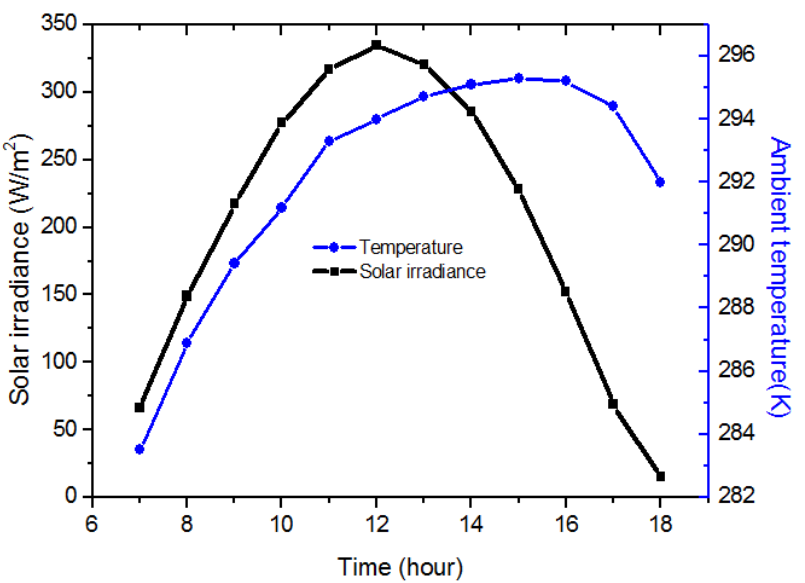

Fig. 4. Variation of solar irradiation and ambient temperature versus time for $04 / 01 / 2020$ 


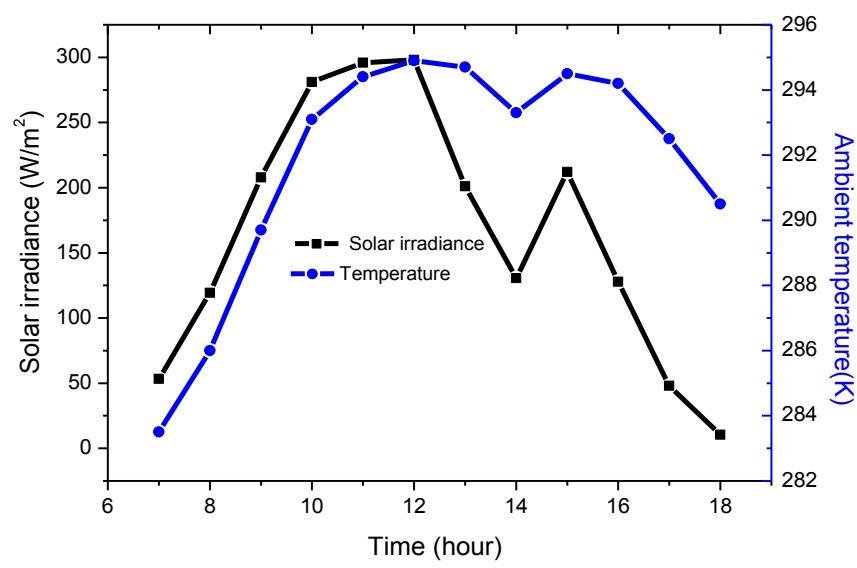

Fig. 5. Variation of solar irradiation and ambient temperature versus time for $04 / 02 / 2020$

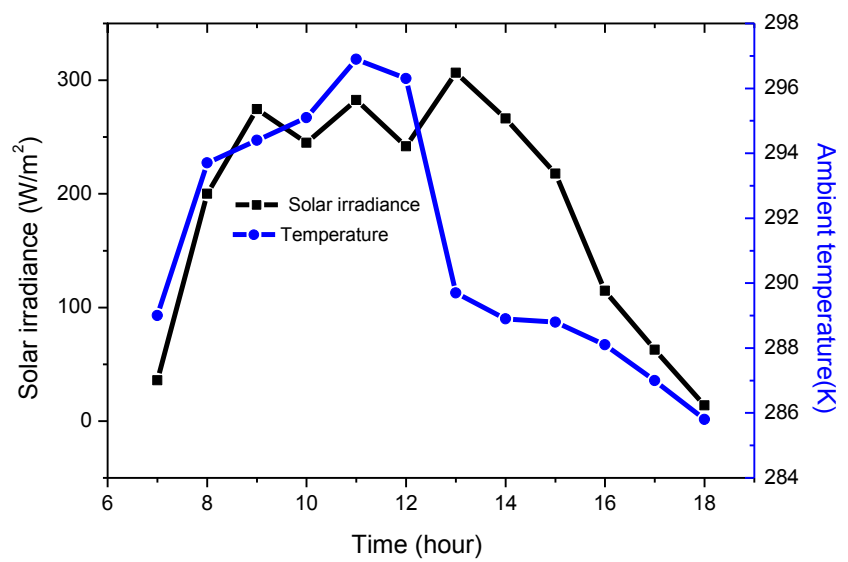

Fig. 6. Variation of solar irradiation and ambient temperature versus time for $04 / 03 / 2020$

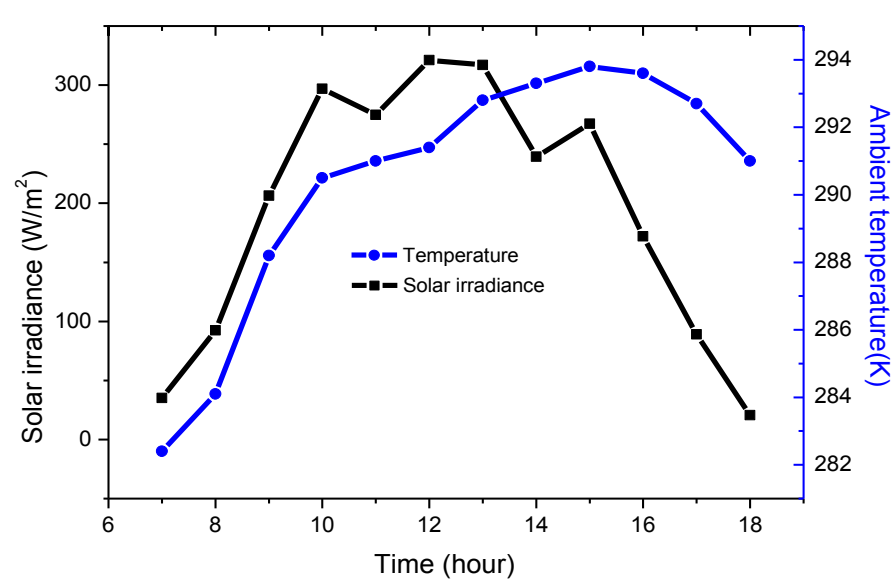

Fig. 7. Variation of solar irradiation and ambient temperature versus time for $04 / 14 / 2020$

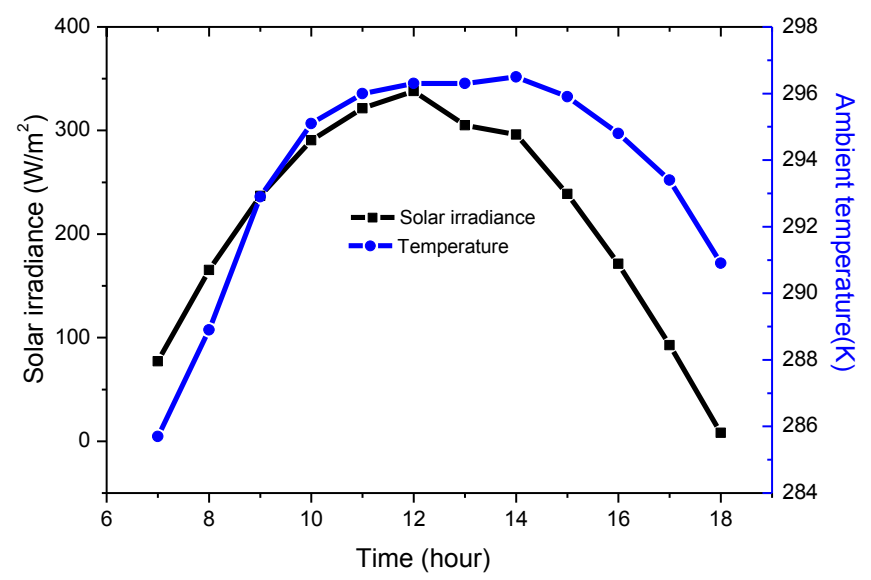

Fig. 8. Variation of solar irradiation and ambient temperature versus time for $04 / 15 / 2020$

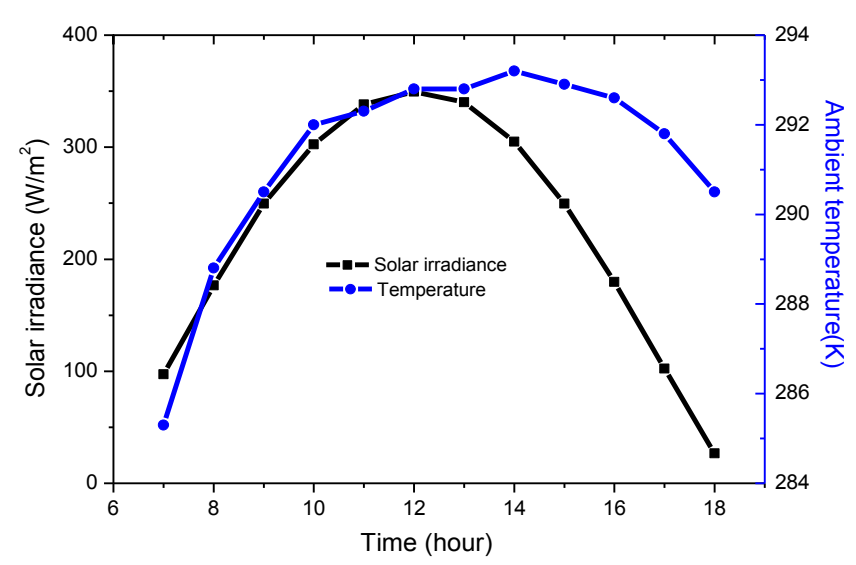

Fig. 9. Variation of solar irradiation and ambient temperature versus time for $04 / 16 / 2020$

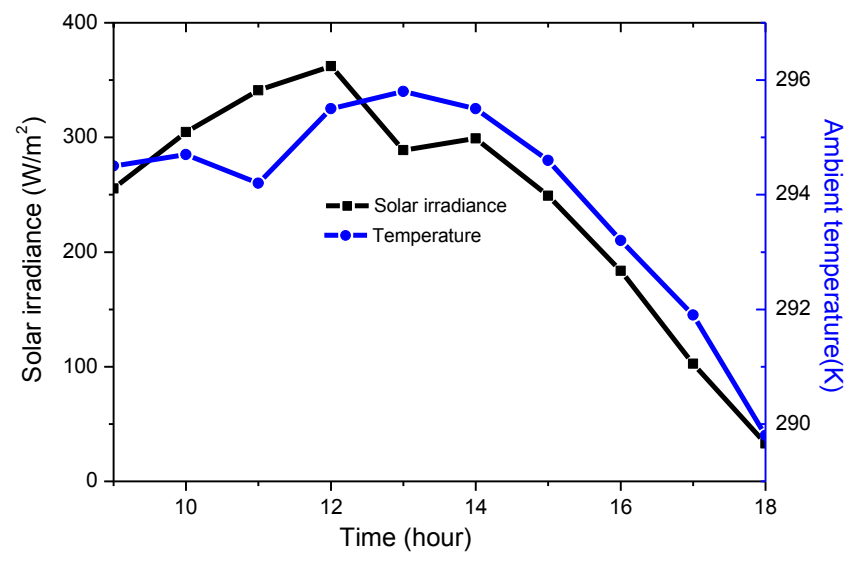

Fig. 10. Variation of solar irradiation and ambient temperature versus time for $04 / 27 / 2020$ 


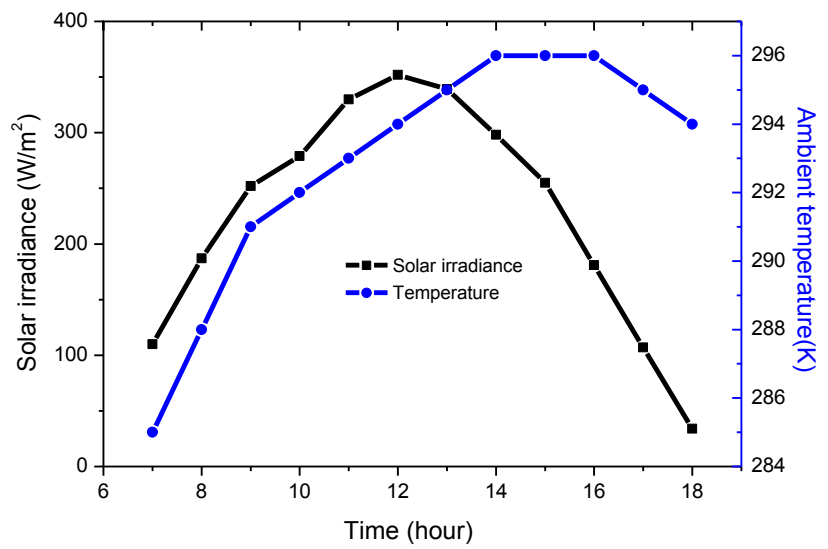

Fig. 11. Variation of solar irradiation and ambient temperature versus time for $04 / 28 / 2020$

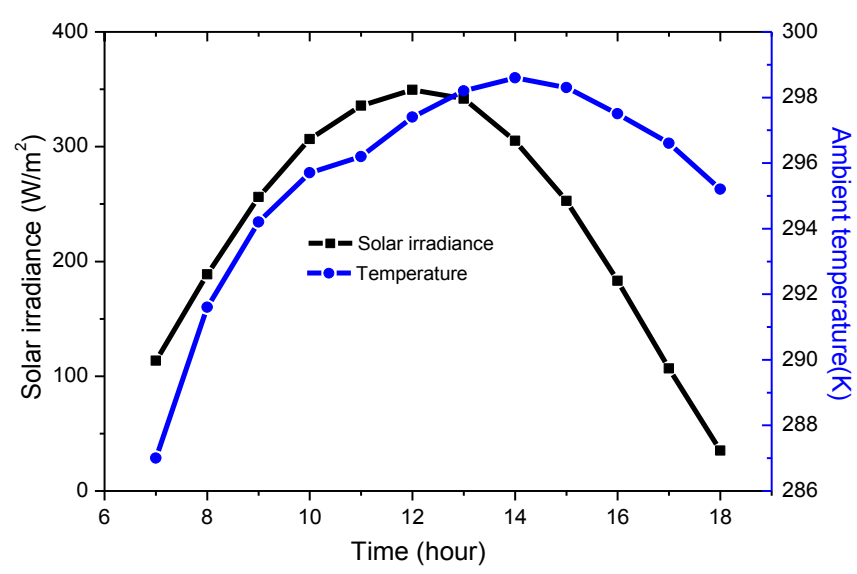

Fig. 12. Variation of solar irradiation and ambient temperature versus time for $04 / 29 / 2020$

It is noticed through the figures 4-12 that all the curves of the solar radiation and ambient temperature have the same shape (Starting from sunrise it increases with time until it reaches its maximum at midday, then it decreases), else the maximum solar radiation is observed between 12 am and $2 \mathrm{pm}$ for all days, but for the temperature at 12 am, except the day of $04 / 03 / 2020$ at 1 p.m.

Figure 13-15 shows the power production by the studied solar chimney power plant versus time for the nine chosen days; the curves have a similar appearance to that of the solar radiation. In addition, we can notice that this production varies during the whole month of April from 50 to $500 \mathrm{KW}$. It should be noted that for large size of solar chimney power plant, the impact of small variations in solar radiation on energy production is negligible.

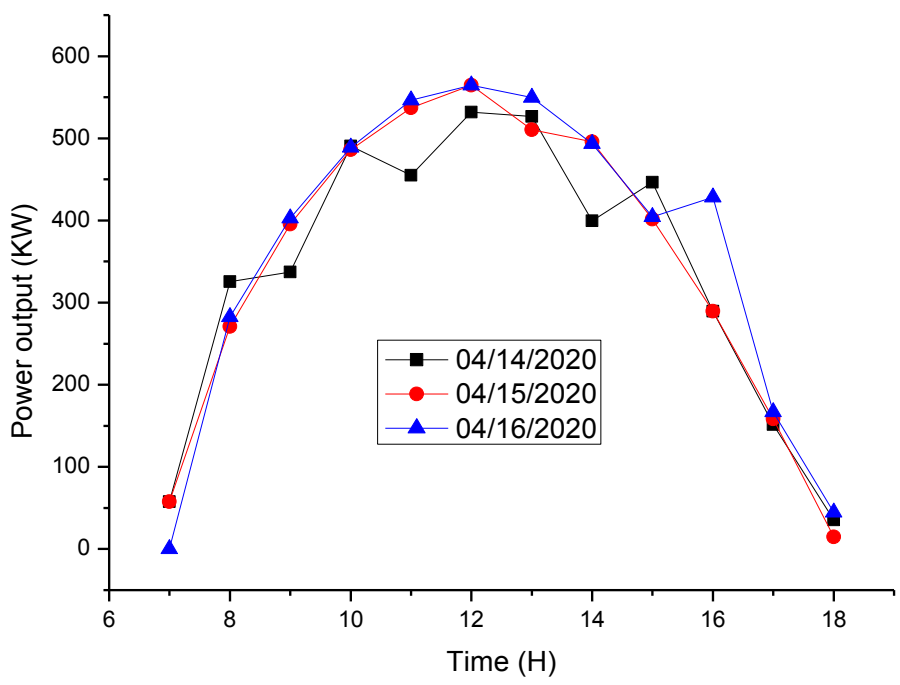

Fig. 13. Variation of generated power during the days of April 1,2 and 3.

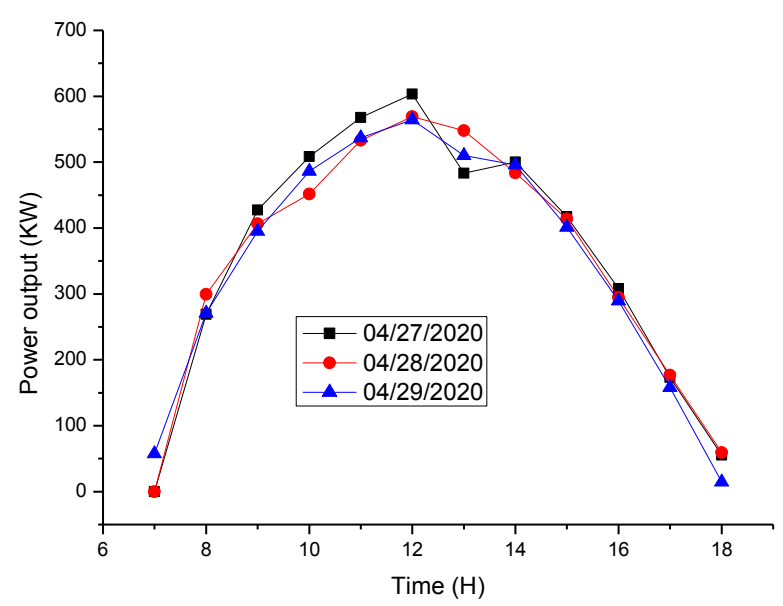

Fig. 14. Variation of generated power during the days of April 14,15 and 16.

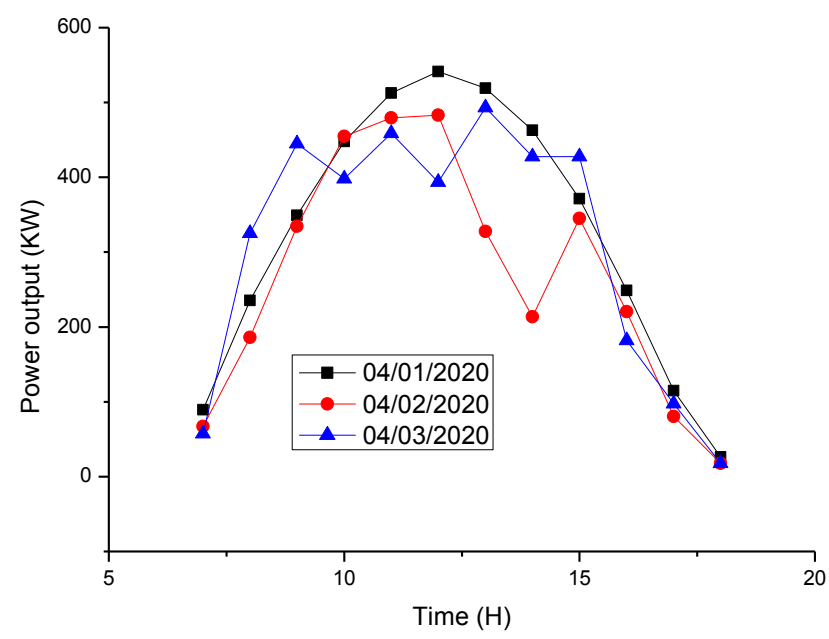

Fig. 15. Variation of generated power during the days of April 27,28 and 29. 


\section{Conclusion}

In this work, the influence of solar radiation and ambient temperature on the generated electrical energy of a solar chimney in the region of Constantine (Algeria) is studied. The results have led to the following notes:

- The production of electrical energy by the simulated power plant is perfectly related to solar radiation and ambient temperature evolutions. Nevertheless, the effect of the first parameter is much important than the second.

- The trend of the variation of energy production is similar to that of solar radiation.

- The average of solar radiation during April 2020 is from $25 \mathrm{~W} / \mathrm{m}^{2}$ up to $120 \mathrm{~W} / \mathrm{m}^{2}$, while ambient temperature is from $282 \mathrm{~K}$ to $292 \mathrm{~K}$.

- The larger dimensions of the chimney plant, the less effect of changes of solar radiation

- The generated power of the installation in the region of Constantine (Algeria) with three times the dimensions of Manzaneres (Spain) prototype, could reach a high range of 270-395 kW. This configuration can enhance the dispatch capacities of such plants, and can reduce the levelized cost of electricity.

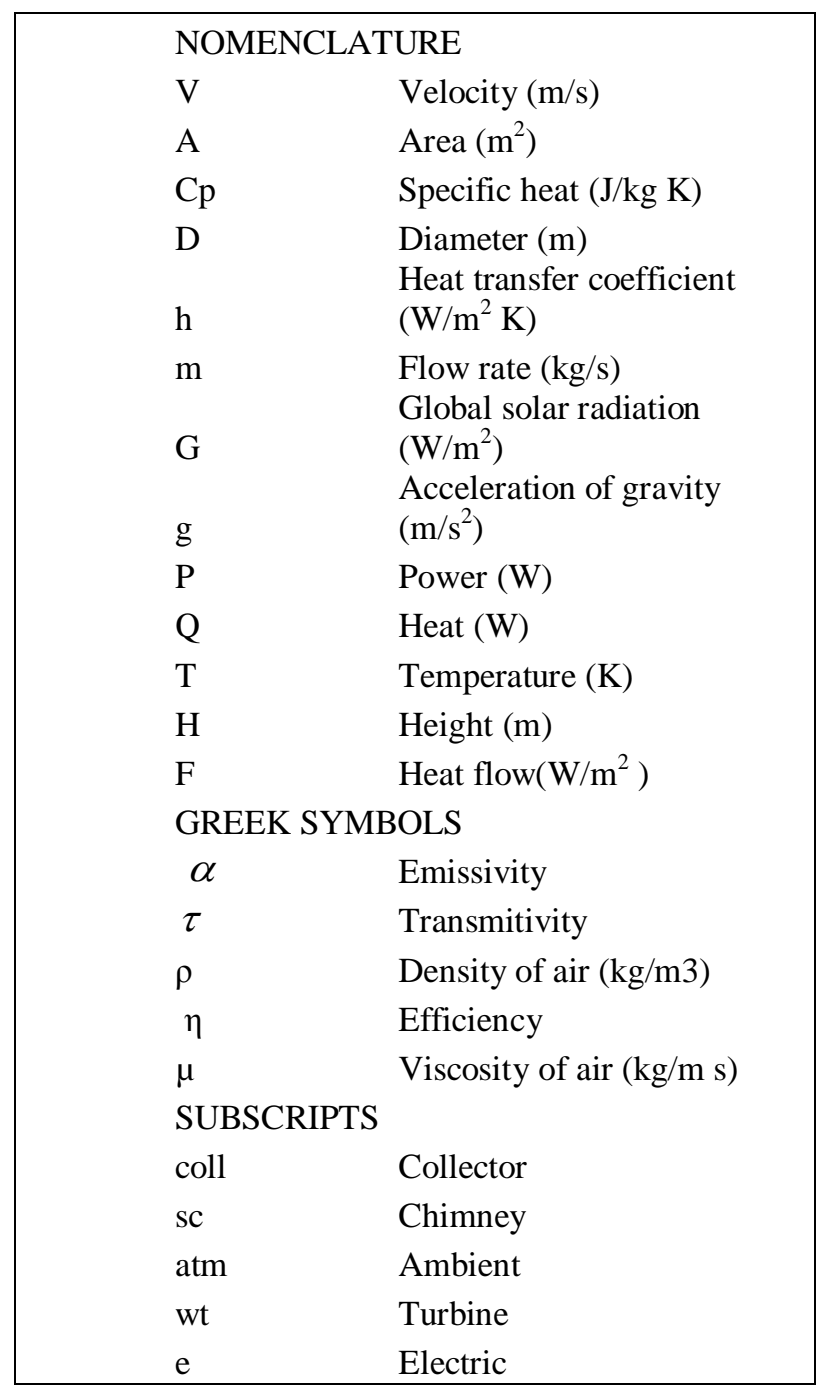

\section{References}

[1] Schlaich J. The solar chimney: electricity from the sun. Edition Axel Menges, 1995.

[2] Schlaich Bergermann und Partner, The Solar Chimney, Structural Consulting Engineers 2002.

[3] A. Asnaghi and S. M. Ladjevardi, "Solar chimney power plant performance in Iran", Renewable and Sustainable Energy Reviews (2012). Vol.16, pp.3383-3390.

[4] Y. J. Dai, H. B. Huang, R. Z. Wang, "Case study of solar chimney power plants in Northwestern regions of China", Renewable Energy (2003). Vol.28, pp.12951304.

[5] S. Djimli and A. Chaker, "Numerical Study of the Solar Chimney Power Plant Performance in the Region of M'Sila-Algeria", The Renewable Energy \& Power Quality Journal (2014). Vol.1, pp.71-75.

[6] S. Djimli and A. Chaker, "Numerical Study the Performance of Solar Chimney Power Plant in Different Regions of Algeria”, Energy conservation (2014). Vol.2, pp.120-125.

[7] C. O Okoye and U. Atikol, "A parametric study on the feasibility of solar chimney power plants in North Cyprus conditions", Energy Conversion and Management (2014). Vol.80, pp.178-187.

[8] W. Haaf, K. Friedrich, G. Mayr, J. Schlaich, "Solar chimneys part I: principle and construction of the pilot plant in Manzanares". International Journal of Solar Energy (1983). Vol. 2, no 1, p. 3-20.

[9] S.V.Patankar, Numerical heat transfer and fluid flow, Hemisphere Publishing Corporation, New York 1980.

[10] Documentation FLUENT: Fluent Inc, July 26,1998.

[11] W. Haaf, "Solar chimneys: part ii: preliminary test results from the Manzanares pilot plant". International Journal of Sustainable Energy (1984). Vol. 2, no 2, p. 141-161.

[12] R. Sangi, M. Amidpour and B. Hosseinizadeh, "Modeling and numerical simulation of solar chimney power plants", Solar energy (2011). Vol. 85, no 5, p. 829-838.

[13] B. Ghorbani, M.Ghashami and M. Ashjaee, "Electricity production with low grade heat in thermal power plants by design improvement of a hybrid dry cooling tower and a solar chimney concept", Energy Conversion and Management (2015). Vol. 94, p. 1-11. 